\title{
Prognostic Significance of CD44 Expression in Hepatocellular Carcinoma Following a Potentially Curative Treatment
}

\author{
Razvan lacob, Vlad Herlea, Codruta Popa, Anca Nastase, Ligia Ghetea, Speranta lacob, Florin Botea, \\ Catalin Pechianu, Razvan Grigorie, Adina Croitoru, Simona Dima, Cristian Gheorghe, Liliana Gheorghe \\ and Irinel Popescu
}

Digestive Diseases and Liver Transplantation Center, Fundeni Clinical Institute, Bucharest, Romania

\section{ABSTACT}

Background/Aim: Liver resection and liver transplantation offer the best chance of survival in hepatocellular carcinoma (HCC), but tumor recurrence still occurs frequently, warranting patient stratification according to the risk of recurrence. Enrichment in stem cell markers is currently a possible risk stratifying strategy. The prognostic significance for HCC recurrence of CD44, a well-established stem cell marker, is still controversial. The aim of our study was to investigate the prognostic significance of CD44 expression in hepatocellular carcinoma following a potentially curative treatment.

Methods: CD44 expression was investigated by qRT-PCR and immunohistochemistry in 31 patients who underwent a potentially curative treatment for HCC. Multivariate survival analysis was conducted using Cox proportional hazards model. Patient HCC related death according to CD44 expression was investigated by Kaplan Meier method.

Results: mRNA quantification has indicated a significant down regulation of CD44 in tumoral vs nontumoral tissue in $35.7 \%$ of cases and a significant up-regulation of gene expression in $9.5 \%$ of cases. Immunohistochemistry has indicated positive CD44 staining in both tumoral and non-tumoral tissue, mainly in non-parenchymal cells and also in a subset of tumoral hepatocytes. CD44 relative gene expression was the only independent predictor of early tumor recurrence, independent of clinical variables as well as for one-year tumor related death.

In conclusion our study brings new evidence for the negative prognostic significance of CD44 expression in hepatocellular carcinoma, indicating a subgroup of patients that need aggressive follow-up after a potentially curative treatment, independent to the kind of surgical treatment performed (liver transplantation or liver resection).

Key words: hepatocellular carcinoma, liver resection, liver transplantation, prognosis, CD44

\section{INTRODUCTION}

Hepatocellular carcinoma (HCC) is the sixth most common neoplasm in the world and the third cause of cancer related death. Each year there are 792,000 new cases and 818,000 liver cancer related deaths (1).
Corresponding author: Irinel Popescu, MD, FACS, FEBS, Professor of Surgery Fundeni Clinical Institute, Digestive Diseases and Liver Transplantation Center 258 Fundeni Street, 022328 Bucharest, Romania E-mail: irinel.popescu@icfundeni.ro

Received: 20.11.2016 Accepted: 14.12 .2016

Copyright ( $)$ Celsius Publishing House 
HCC represents more than $90 \%$ of liver cancers and develops in $80 \%$ of cases in patients with cirrhotic livers (2). Despite advances in prevention techniques, screening, and new technologies in diagnosis and treatment, incidence and mortality continue to rise. Hepatitis B virus and hepatitis $C$ virus leading to cirrhosis remain the most powerful risk factors for HCC, conferring an annual risk of developing $\mathrm{HCC}$ of approximately $5 \%$.

Selection of a treatment modality is based on tumor size, location, extrahepatic spread, underlying liver function and usually requires a multidisciplinary approach (3). Liver resection and liver transplantation are the main therapeutic curative options in the case of $\mathrm{HCC}$ with or without associated liver cirrhosis.

However, the 1-, 3-, and 5-year survival have been reported to be $85 \%, 62 \%$, and $51 \%$ for resection and $84 \%, 69 \%$, and $69 \%$ for transplantation for patients with early HCC (4).

Consequently to the poor prognosis of this cancer, a translational approach is required to personalized clinical decision making, to improve survival of HCC patients. Molecular signatures derived from tumor and non-tumor samples are associated with early tumor recurrence due to metastasis and late tumor recurrence due to de novo carcinogenesis after curative treatment, respectively. Identification of patients with a high risk of relapse will guide adjuvant therapy randomized clinical trials and also select patients that require aggressive follow-up for detection of an early tumor recurrence (5).

There have been described cells within the HCC cellular population that express stem/progenitor cells specific markers, designating tumor stem cells. Several cell surface markers have been proposed for identification of HCC stem cells both in vivo and in vitro (6): CD13, CD133, CD24, CD44, CD90, DLK1, EPCAM, OV6 (7-9)

CD44 has been reported to have multiple functions related to migration, adhesion and invasion and prognostic significance has been investigated in many cancers: liver, kidney, thyroid gland, colorectal (10).

In the liver, CD44 is a major receptor for hyaluronic acid and osteopontin, critical mediators of fibrogenesis in cirrhosis and has been investigated by multiple studies in relationship with clinicopathological features of HCC or as a prognostic factor, so far with conflicting results (11-13).

The aim of our study was to investigate CD44 expression pattern in HCC and its prognostic significance following a potentially curative treatment (liver resection or liver transplantation).

\section{MATERIALS AND METHODS}

Thirty one patients following a potentially curative treatment for HCC in a Tertiary Digestive Diseases Centre have been consecutively included in our study. Tissue specimens have been harvested at the time of surgery by the pathologist and preserved in our Hospital Tissue Bank. Liver transplantation policy in our Center has been previously described (14). All patients provided informed consent for tissue prelevation and tissue banking for participation in the study.

\section{Patients follow-up}

The following clinical variables were recorded preoperatively and after the histopathological analysis of the surgical specimen: age, sex, liver disease etiology, Child-Pugh classification of underlying liver disease, number of tumors, maximal tumor diameter, preoperative AFP levels, Edmondson-Steiner grading. Only patients with a histologically proven HCC were included in the study. After treatment, patients were followed-up by abdominal ultrasound every three months, abdomen and chest CT scans and AFP level every 6 months during the first two years and yearly thereafter. Tumor recurrence and patient death were recorded for survival analysis.

\section{Liver tissue samples}

Tumoral (T) and paired non-tumoral cirrhotic tissue samples (C) were collected by a trained pathologist from surgical specimens immediately after procedure (liver resection or liver transplantation), stored in RNALater (Sigma, St. Louis, MO) and deep-frozen in liquid nitrogen subsequently. For transcriptomic analysis total RNA was isolated from frozen tumoral and non-tumoral tissue samples using TRI Reagent ${ }^{\circledR}$ (Sigma, St. Louis, MO) according to recommended protocol.

\section{RNA extraction and quantitative gene expression analysis}

Total RNA was purified from tissue samples using RNEasy Mini kit (Qiagen) according to manufacturer's instructions. The quantity and quality of the total RNA were assessed by spectrophotometry with Nano Drop 1000 (Thermo Scientific, Arlington, TX) and by using lab-on-a-chip Agilent 2100 technology (Agilent Technology, Santa Clara, CA). Only samples with RNA Integrity Number higher that 8.0 were used for further analysis. 1 ug RNA/sample was subjected to reverse transcription using RT2 First Strand Kit (Qiagen). Gene expression quantification has been performed in duplicate using a Custom RT2 Profiler PCR Array (Qiagen). 
Beta-actin was used as internal control gene.

The custom made array uses validated primer pairs and has multiple qPCR quality controls: genomic DNA contamination control, reverse transcription control, positive GPCR control. Fold changes in gene expression were calculated in comparison $\mathrm{T}$ vs $\mathrm{C}$ tissue samples, using comparative $\mathrm{Ct}$ method [2^(-delta delta $\mathrm{Ct})$ ]. Significant down regulation was considered for $<0.5$ fold change in relative gene expression, significant upregulation for $>2$ fold change.

\section{Immunohistochemistry}

Immunohistochemistry was conducted on paraffin embedded tissue samples using CD44 Monoclonal Antibody (156-3C11) (Thermo Fisher Scientific) and UltraVision Quanto Detection System HRP DAB (Thermo Fisher Scientific) according to manufacturer's instructions.

\section{Statistical analysis}

Quantitative data has been expressed as mean \pm standard deviation. Categorical data has been expressed as percentage of patients in a specific category. Multivariate survival analysis has been conducted by Cox proportional hazards model, having early tumor recurrence (within 24 months) as an outcome. CD44 relative gene expression was included as a covariate in the multivariate analysis, together with clinical variables. Survival curves have been depicted as Kaplan Meier plots and compared using log-rank test. A p-value $<0.05$ has been used for statistical significance.

\section{RESULTS}

In our cohort, tumor recurrence was diagnosed in $51.6 \%$ of patients following a potentially curative treatment with highest rate in patients following livingrelated liver transplantation. Patient's tumor relateddeath during follow-up occurred in $25.8 \%$ of cases. Patient's characteristics are depicted in table 1.

mRNA quantification has indicated a significant down regulation of CD44 in tumoral vs non-tumoral tissue in $35.7 \%$ of cases and a significant up-regulation of gene expression in $9.5 \%$ of cases.

Immunohistochemical staining of tumoral and nontumoral adjacent tissue has indicated positive CD44 expression in non-parenchymal cells in both tumor and adjacent cirrhotic tissue, in all the studied cases.

The number of positive non-parenchymal cells, however, was lower in a subset of tumoral nodules as compared to non-tumoral tissue, in concordance with the mRNA gene expression (fig. 1). The cells marking
Table 1 - Patients clinical characteristics

\begin{tabular}{|c|c|}
\hline Age & $57.3 \pm 11.5$ ys \\
\hline Male Sex & $74.2 \%$ \\
\hline \multicolumn{2}{|l|}{ Etiology } \\
\hline $\mathrm{VHB}+\mathrm{VHD}$ & $22.6 \%$ \\
\hline VHB & $35.5 \%$ \\
\hline VHC & $41.9 \%$ \\
\hline \multicolumn{2}{|l|}{ Pre-therapeutic Child Pugh class } \\
\hline Child-Pugh A & $73.1 \%$ \\
\hline Child-Pugh B & $11.5 \%$ \\
\hline Child-Pugh C & $15.4 \%$ \\
\hline \multicolumn{2}{|l|}{ AFP level } \\
\hline AFP (ng/ml) & $6060.5 \pm 17120.1$ \\
\hline AFP $>100 \mathrm{ng} / \mathrm{ml}$ & $40.7 \%$ \\
\hline AFP $>300 \mathrm{ng} / \mathrm{ml}$ & $38.5 \%$ \\
\hline \multicolumn{2}{|l|}{ Tumor grading } \\
\hline Well differentiated & $16.1 \%$ \\
\hline Moderately/poorly differentiated & $83.9 \%$ \\
\hline \multicolumn{2}{|l|}{ Number of tumoral nodules } \\
\hline No. tumoral nodules 1 & $74.2 \%$ \\
\hline No. tumoral nodules 2 & $16.1 \%$ \\
\hline No. tumoral nodules $\geq 3$ & $9.7 \%$ \\
\hline Diameter of largest tumor & $6.9 \pm 4.3 \mathrm{~cm}$ \\
\hline \multicolumn{2}{|l|}{ Within Milan criteria } \\
\hline Yes & $40.0 \%$ \\
\hline No & $60.0 \%$ \\
\hline \multicolumn{2}{|l|}{ Type of curative treatment } \\
\hline Liver resection & $61.3 \%$ \\
\hline DD - LTx & $25.8 \%$ \\
\hline LD-LTx & $12.9 \%$ \\
\hline Follow-up (months) & $28 \pm 15.8$ \\
\hline \multicolumn{2}{|l|}{ Tumor recurrence during follow-up } \\
\hline Overall & $51.6 \%$ \\
\hline Liver resection & $57.8 \%$ \\
\hline DD-LTx & $25 \%$ \\
\hline LD-LTx & $60 \%$ \\
\hline Median time to recurrence (months) & $20.4 \pm 15.9$ months \\
\hline \multicolumn{2}{|l|}{ Recurrence rate in the first 24 months } \\
\hline Overall & $45.2 \%$ \\
\hline Liver resection & $47.3 \%$ \\
\hline DD-LTx & $25 \%$ \\
\hline LD-LTx & $60 \%$ \\
\hline \multicolumn{2}{|l|}{ Death rate during follow-up } \\
\hline Overall & $25.8 \%$ \\
\hline Liver resection & $26.3 \%$ \\
\hline DD-LTx & $25 \%$ \\
\hline LD-LTx & $25 \%$ \\
\hline
\end{tabular}

the border between tumor and cirrhotic adjacent tissue were also CD44 positive (fig. 2).

CD44 positive clustered tumoral hepatocytes were identified in a subset of tumors (fig. 3).

There was no statistically significant correlation between CD44 mRNA expression levels and clinical variables: age, sex, disease etiology, AFP level, Edmondson-Steiner grading, Child-Pugh class, number of tumors, the diameter of the largest tumor or the distribution of patients according to Milan criteria (table 2).

The predictive value of $\mathrm{CD} 44$ relative gene quantification for early tumor recurrence (in the first 24 


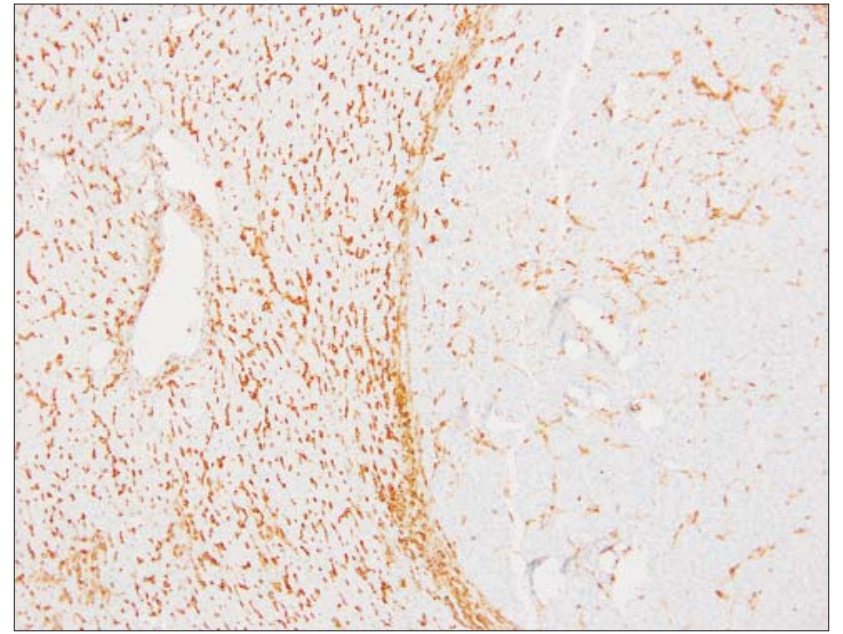

Figure 1 - CD44 expression in tumoral vs non-tumoral tissue. Immunohistochemical stain $\times 10$. CD44 positive non-parenchymal cells could be identified both in HCC nodule and adjacent cirrhotic tissue with a higher expression in non-tumoral tissue. CD44 positive cells could be identified at the interface tumoralnon-tumoral tissue, clearly delineating the tumor border

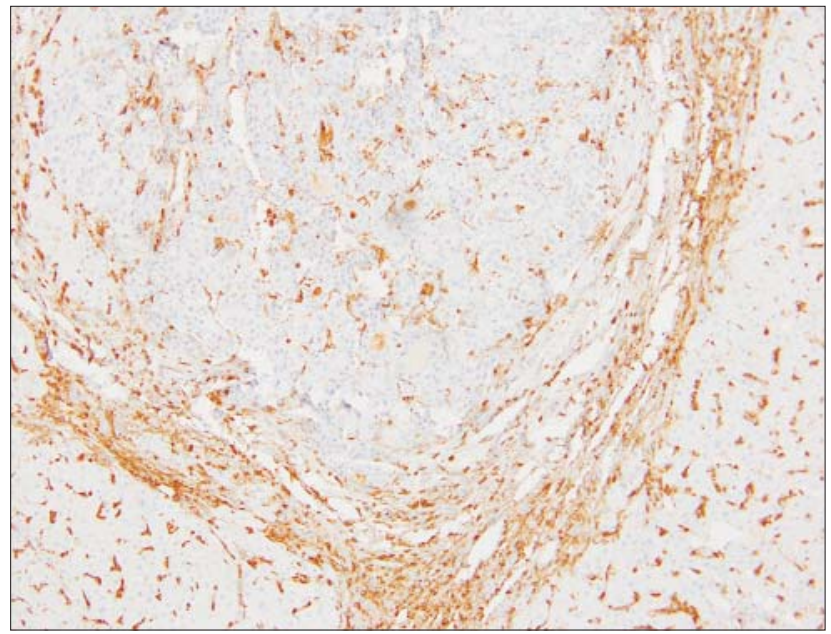

Figure 2 - CD44 expression in tumoral vs non-tumoral tissue. Immunohistochemical stain $\times 20$. CD44 positive cells delineating the tumor border

months following the therapeutic procedure) was investigated by Cox proportional hazards regression.

The following variables have been included as covariates in the multivariate survival analysis: CD44 relative gene expression, AFP $>300 \mathrm{ng} / \mathrm{ml}$, EdmondsonSteiner grading - Well - differentiated, Milan criteria, type of surgical procedure. CD44 relative gene expression was the only independent predictor of early tumor recurrence (table 3).

Significant tumoral up-regulation of CD44 (>2 fold change in relative gene expression) was also a predictor of early tumor related patient death following the therapeutic procedure, according to Kaplan Meier survival curves ( $p=0.03$ - log rank test) (fig. 4).

\section{DISCUSSION}

CD44 is an important adhesion molecule that mediates cellular-matrix interactions and also a documented mesenchymal stem cell marker involved in paracrine intercellular communication (15). CD44 defines a family of class I transmembrane proteins produced by alternate splicing leading to variation in the extracellular membrane -proximal portion of the protein, encoded by variant exons v1-v10 (16). It has been reported that spliced variant forms $v 6$ and $v 7$ of CD44 constitute binding sites for osteopontin (17), a multifunctional protein with complex roles mediating inflammation, fibrogenesis, angiogenesis and carcinogenesis in multiple organs including the liver (18). In the liver, CD44 is also a receptor for hyaluronic acid, an

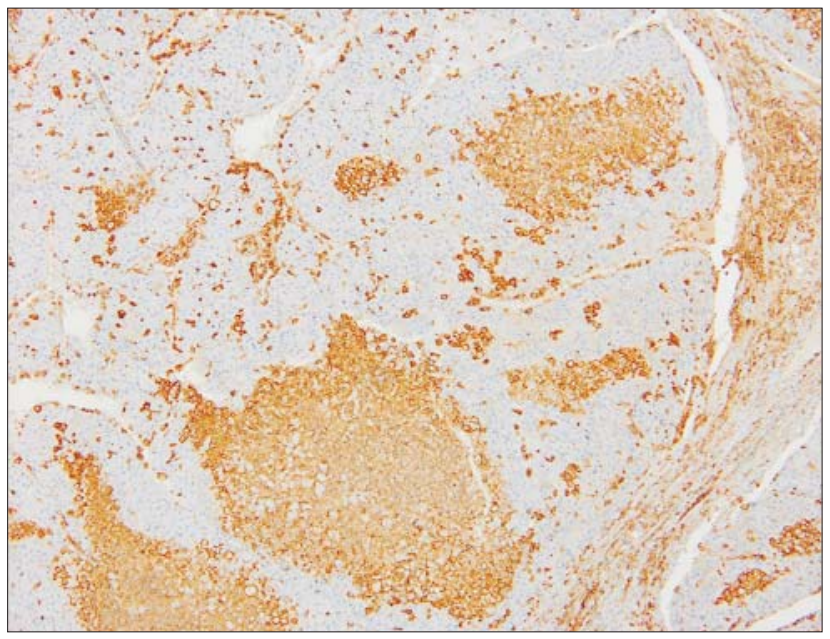

Figure 3 - CD44 expression in hepatocellular carcinoma. Immunohistochemical stain $\times 10$. Clusters of CD44 positive tumoral hepatocytes could be identified in a subset of tumors

important mediator of liver fibrogenesis, being the main regulator for its metabolism (19).

In the present study we have found supporting evidence for the prognostic significance of CD44 gene expression in hepatocellular carcinoma with regard to tumor recurrence after a potentially curative treatment, as well as for early patient death due to HCC recurrence. In our study CD44 was the only independent predictor of early tumor recurrence, stronger than classical clinical predictors, independent of the type of surgical procedure (liver resection or liver transplantation).

Although there are multiple studies investigating 
Table 2 - Clinical characteristics of patients in the study group according to different CD44 levels of gene expression

\begin{tabular}{|c|c|c|c|c|}
\hline & CD44 downregulation & CD44-N & CD44 upregulation & P-value \\
\hline \multicolumn{5}{|l|}{$\overline{\text { Sex }}$} \\
\hline Female & 20.00 & 26.08 & 75.00 & \\
\hline Male & 80.00 & 73.92 & 25.00 & 0.08 \\
\hline \multicolumn{5}{|l|}{ Age $>60$ years } \\
\hline No & 40.00 & 52.17 & 50.00 & \\
\hline Yes & 60.00 & 47.83 & 50.00 & 0.87 \\
\hline \multicolumn{5}{|l|}{ Liver Disease Etiology } \\
\hline $\mathrm{HBV}=\mathrm{No}_{0}$ & 60.00 & 60.87 & 100.00 & \\
\hline $\mathrm{HBV}=\mathrm{Yes}$ & 40.00 & 39.13 & 0.00 & 0.29 \\
\hline $\mathrm{HCV}=\mathrm{No}$ & 53.33 & 65.22 & 25.00 & \\
\hline $\mathrm{HCV}=\mathrm{Yes}$ & 46.67 & 34.78 & 75.00 & 0.30 \\
\hline $\mathrm{HBV}+\mathrm{HDV}=\mathrm{No}$ & 86.67 & 69.57 & 75.00 & \\
\hline $\mathrm{HBV}+\mathrm{HDV}=\mathrm{Yes}$ & 13.33 & 30.43 & 25.00 & 0.48 \\
\hline \multicolumn{5}{|l|}{ AFP level $(\mathrm{ng} / \mathrm{ml})$} \\
\hline AFP $<100$ & 42.86 & 70.00 & 75.00 & \\
\hline AFP $>100$ & 57.14 & 30.00 & 25.00 & 0.11 \\
\hline \multicolumn{5}{|l|}{ Edmondson - Steiner Grading } \\
\hline Well differentiated & 92.86 & 17.39 & 0.00 & \\
\hline Moderately-Poorly differentiated & 7.14 & 82.61 & 100.00 & 0.81 \\
\hline \multicolumn{5}{|l|}{ Severity of Liver Disease } \\
\hline Child-Pugh A & 78.57 & 68.42 & 50.00 & \\
\hline Child Pugh B & 14.29 & 15.79 & 50.00 & \\
\hline Child-Pugh C & 7.14 & 15.79 & 0.00 & 0.44 \\
\hline \multicolumn{5}{|l|}{ Tumor number } \\
\hline Tumor Numer: 1 & 86.67 & 65.22 & 100.00 & \\
\hline Tumor Number: 2 & 13.33 & 17.39 & 0.00 & \\
\hline Tumor Number $\geq 3$ & 0.00 & 17.39 & 0.00 & 0.29 \\
\hline \multicolumn{5}{|l|}{ Diameter of the largest tumor } \\
\hline Tumor diameter $<5 \mathrm{~cm}$ & 53.33 & 39.13 & 33.33 & \\
\hline Tumor diameter $\geq 5 \mathrm{~cm}$ & 46.67 & 60.87 & 66.67 & 0.64 \\
\hline \multicolumn{5}{|l|}{ Milan Criteria met } \\
\hline No & 53.33 & 73.91 & 50.00 & \\
\hline Yes & 46.67 & 26.09 & 50.00 & 0.35 \\
\hline
\end{tabular}

Table 3 - Results of multivariate survival analysis by Cox Proportional Hazards Model

\begin{tabular}{lccc}
\hline Covariate & HR & 95\% Cl of HR & P \\
\hline CD44 relative expression & 1.84 & 1.03 to 3.2915 & 0.03 \\
\hdashline AFP $>300 \mathrm{ng} / \mathrm{ml}$ & 2.78 & 0.88 to 8.75 & 0.08 \\
\hline
\end{tabular}

the clinical relevance and prognostic significance of CD44 expression in HCC, data is still conflicting.

In the study conducted by Mima $\mathrm{K}$ et al, CD 44 expression was investigated in $5 \mathrm{HCC}$ cell lines (PLC/PRF/5, HuH1, HLF, HLE and SK HEP-1), the authors concluding that CD44v6 expression is correlated with an invasive phenotype, but the result did not appear to be clinically significant. The study conducted by the same group in $150 \mathrm{HCC}$ patients who underwent liver resection for HCC indicated only $30.7 \%$ positive for CD44v6 expression: $21.3 \%<25 \%$ positivity, $6 \% 25-50 \%$ positivity and $3.3 \%>50 \%$ positivity with no positive cell identified in adjacent liver tissue. There was a trend of association between a low CD44v6 expression and the vascular invasion in HCC patients and there was no significant association between high CD44v6 expression and disease-free survival, by Kaplan-Meier method (20).

In contrast, Mathew et al have shown that high expression of CD44s (standard isoform of CD44) was associated with increased rate of vascular invasion (21). In the study by Endo et al, CD44 protein expression correlated with reduced survival and was identified by multivariate survival analysis as the single independent prognostic factor (22). In a study conducted on a cohort of 260 patients with HCC by tissue microarray analysis, CD44s protein expression correlated with histological grade (poorly differentiated according to Edmondson grading system) and was also identified by univariate and multivariate survival analysis as a negative prognostic factor (23). 
Figure 4 - Kaplan Meier survival curves according to CD44 expression. Tumoral over-expression of CD44 is associated with earlier patient's death due to HCC recurrence $(\log$ rank test $p=0.03)$

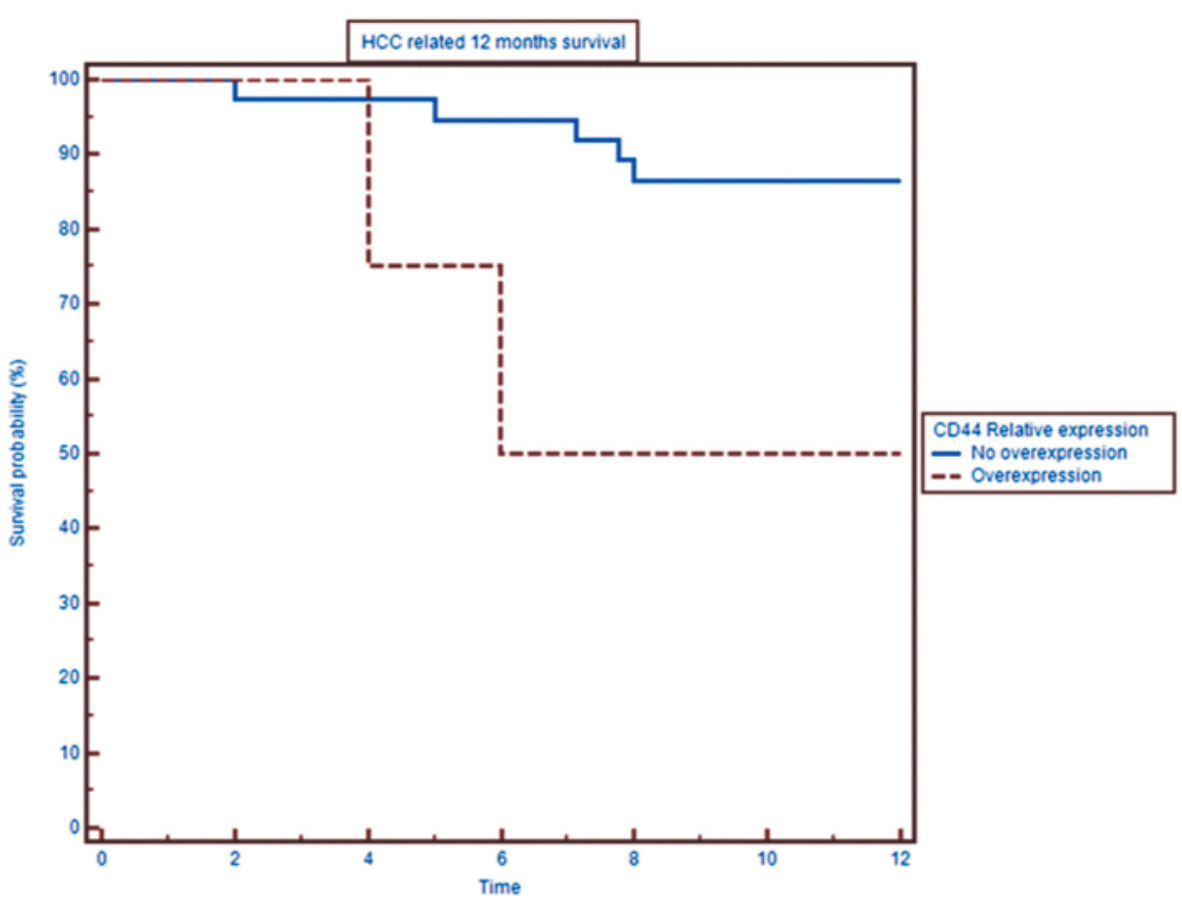

Expression of osteopontin and its main receptor CD44 was investigated at mRNA and protein level in tumor tissue and surrounding hepatic parenchyma, in 53 patients who underwent liver resection for HCC (24). Expression of OPN and CD44s was significantly higher in HCC compared with adjacent non-tumor tissue both proteins being significantly overexpressed in HCC lesions with positive lymph nodes. However, there was no significant correlation between patient survival and OPN and CD44s expression (24).

In our study, there was no significant difference in CD44 mRNA gene expression between tumor and nontumoral adjacent tissue in $54.8 \%$ of cases and overexpression of CD44 gene was identified in $9.5 \%$ of cases. There was strong expression of CD44 protein in cells located at the tumor margin, at the interface with the non-tumoral cirrhotic tissue, possibly marking the tumor invasion front. If these cells are positive CD44 hepatocyes or non-parenchymal cells is an important question to be answered by subsequent studies.

There is a clear difference between the expressions profiles of CD44 in human studies in comparison to studies conducted in animal models of liver injury. In a classical oval cells model, the rat model of liver injury induced by 2 acetylaminofluorene treatment followed by partial hepatectomy (2AAF-PH), Affymetrix analyses indicated high CD44 expression levels in the oval cells enriched fraction. Also hepatoblasts and FAO-1 hepatoma cells were positive for CD44. In normal rat liver, CD44 was positive in small bile ducts, co-localizing with CK19 and also in scattered blood-cells from the periportal region (also positive for $\mathrm{CD} 45$ ). In $2 \mathrm{AAF} / \mathrm{PH}$ treated animals, CD44 was strongly positive in oval cells but not in endothelial cells, Kupfer cells or stellate cells (25). According to our study, in liver cirrhosis mainly the non-parenchymal cells, probably liver endothelial cells or stellate cells, have a strong positive CD44 staining, supporting the idea that the oval cell theory is not applicable in the human setting of chronic liver disease. Due to ubiquitous expression of CD44 in both nontumoral and intra-tumoral nonparenchymal cells, our result also emphasise the important prognostic significance of the HCC environment in the cirrhotic context, more than the cancer stem cell theory. Although clusters of CD44 positive malignant hepatocytes could also be identified, the exact nature or origin of those cells is still elusive and should be investigated by subsequent co-localisation studies with other stem cell markers.

\section{CONCLUSION}

In conclusion our study brings new evidence for the negative prognostic significance of CD44 expression in hepatocellular carcinoma indicating a subgroup of patients that need aggressive follow-up after a poten- 
tially curative treatment, irrespective of the type of treatment performed (liver transplantation or liver resection).

\section{Acknowledgment}

The Paper was supported by the Research Grants UEFISCDI PCE 125/2011 and 4 SEE/30.06.2014 Ro140018 - Hepmark.

\section{REFERENCES}

1. Global Burden of Disease Cancer Collaboration, Fitzmaurice C, et al. The Global Burden of Cancer 2013. JAMA Oncol. 2015;1(4):505-27.

2. Llovet JM. Updated treatment approach to hepatocellular carcinoma. J Gastroenterol 2005; 40(3):225-35

3. Balogh J, Victor D 3rd, Asham EH, Burroughs SG, Boktour M, Saharia A, Li X, Ghobrial RM, Monsour HP Jr. Hepatocellular carcinoma: a review. J Hepatocell Carcinoma. 2016;3:41-53

4. Llovet JM, Fuster J, Bruix J. Intention-to-treat analysis of surgical treatment for early hepatocellular carcinoma: resection versus transplantation. Hepatology. 1999;30(6):1434-40.

5. Pinyol R, Nault JC, Quetglas IM, Zucman-Rossi J, Llovet JM. Molecular profiling of liver tumors: classification and clinical translation for decision making. Semin Liver Dis. 2014;34(4):363-75.

6. Yamashita T, Wang XW. Cancer stem cells in the development of liver cancer. J Clin Invest. 2013 May;123(5):1911-8. doi: 10.1172/ JCl66024. Epub 2013 May 1.

7. Ishimoto T, Nagano O, Yae T, Tamada M, Motohara T, Oshima H, et al. CD44 variant regulates redox status in cancer cells by stabilizing the XCT subunit of system XC(-) and thereby promotes tumor growth. Cancer Cell. 2011 Mar 8;19(3):387-400. doi: 10.1016/j.ccr.2011. 01.038.

8. Yamashita $\mathrm{T}$, Honda M, Nakamoto $\mathrm{Y}$, Baba M, Nio K, Hara $\mathrm{Y}$, et al. Discrete nature of EpCAM+ and CD90+ cancer stem cells in human hepatocellular carcinoma. Hepatology. 2013 Apr;57(4):1484-97. doi: 10.1002/hep.26168. Epub 2013 Jan 18.

9. Yang ZF, Ngai P, Ho DW, Yu WC, Ng MN, Lau CK, et al. Identification of local and circulating cancer stem cells in human liver cancer. Hepatology. 2008 Mar;47(3):919-28. doi: 10.1002/hep.22082.

10. Naor D, Nedvetzki S, Golan I, Melnik L, Faitelson Y. CD44 in cancer. Crit Rev Clin Lab Sci. 2002 Nov;39(6):527-79.

11. Hu S, Wu X, Zhou B, Xu Z, Qin J, Lu H, et al. IMP3 combined with $\mathrm{CD} 44 \mathrm{~s}$, a novel predictor for prognosis of patients with hepatocellular carcinoma. J Cancer Res Clin Oncol. 2014 Jun;140(6):883-93. doi: 10.1007/s00432-014-1639-x. Epub 2014 Mar 20.

12. Huang KH, Yuan SZ. Study of significace of CD44v6 expression in hepatocellular carcinoma. Chin J Cancer 2001. 20(2); 200-1.
13. Zhang KL, Wang ZM, Wei SD. Significance of CD44v6 and c-Met expression in hepatocellular carcinoma. Chin J Gener Surg 2008; 17(1): 94-7.

14. lacob R, lacob S, Gheorghe L, Gheorghe C, Hrehoret D, Brasoveanu V, et al. Outcome of liver transplantation for hepatocellular carcinoma - a single center experience. Chirurgia (Bucur). 2013 Jul-Aug;108(4):44650.

15. Ramos T, Sánchez-Abarca LI, Muntión S, Preciado S, Puig N, LópezRuano G, et al. MSC surface markers (CD44, CD73, and CD90) can identify human MSC-derived extracellular vesicles by conventional flow cytometry. Cell Commun Signal. 2016 Jan 12;14:2. doi: 10.1186/ s12964-015-0124-8.

16. Günthert U, Hofmann M, Rudy W, Reber S, Zöller M, Haussmann I, et al. A new variant of glycoprotein CD44 confers metastatic potential to rat carcinoma cells. Cell. 1991 Apr 5;65(1):13-24.

17. Katagiri YU, Sleeman J, Fujji H, Herrlich P, Hotta H, Tanaka K, et al. CD44 variants but not CD44s cooperate with beta1-containing integrins to permit cells to bind to osteopontin independently of arginine-glycine-aspartic acid, thereby stimulating cell motility and chemotaxis. Cancer research. 1999; 59: 219-26.

18. Wen Y, Jeong S, Xia Q, Kong X. Role of Osteopontin in Liver Diseases. Int J Biol Sci. 2016 Aug 6;12(9):1121-8. doi: 10.7150/ijbs.16445. eCollection 2016.

19. Yasuda M, Nakano K, Yasumoto K, Tanaka Y. CD44: Functional relevance to inflammation and malignancy. Histol Histopatol 2002; 17: $945-950$

20. Mima K, Okabe H, Ishimoto T, Hayashi H, Nakagawa S, Kuroki H, et al. The expression levels of CD44v6 are correlated with the invasiveness of hepatocellular carcinoma in vitro, but do not appear to be clinically significant. Oncol Lett. 2012 May;3(5):1047-1051. Epub 2012 Feb 17.

21. Mathew J, Hines JE, Obafunwa JO, Burr AW, Toole K, Burt AD. CD44 is expressed in hepatocellular carcinomas showing vascular invasion. J Pathol 1996;179:74-79.

22. Endo K, Terada T. Protein expression of CD44 (standard and variant isoforms) in hepatocellular carcinoma: relationships with tumor grade, clinicopathologic parameters, p53 expression, and patient survival. J Hepatol 2000;32:78-84.

23. Ryu HS, Park SH, Lee KB, Shin E, Jang JJ. Expression of the Transmembrane Glycoprotein CD44s Is Potentially an Independent Predictor of Recurrence in Hepatocellular Carcinoma. Gut Liver. 2011 Jun;5(2):204-9. doi: 10.5009/gnl.2011.5.2.204. Epub 2011 Jun 23.

24. Beckebaum S, Chen X, Sotiropoulos GC, Radtke A, Daoudaki M, Baba $H A$, et al. Role of osteopontin and CD44s expression for patients with hepatocellular carcinoma undergoing liver transplantation or resection. Transplant Proc. 2008 Nov;40(9):3182-4. doi: 10.1016/ j.transproceed.2008.08.034.

25. Yovchev MI, Grozdanov PN, Zhou H, Racherla H, Guha C, Dabeva MD. Identification of adult hepatic progenitor cells capable of repopulating injured rat liver. Hepatology. 2008 Feb;47(2):636-47. 